\title{
SEROLOGICAL DIFFERENTIATION OF OBSTRUCTIVE FROM HEPATOGENOUS JAUNDICE BY FLOCCULATION OF CEPHALIN-CHOLESTEROL EMULSIONS
}

\author{
By FRANKLIN M. HANGER \\ (From the Department of Medicine, College of Physicians and Surgeons, Columbia University, \\ and the Presbyterian Hospital, New York City)
}

(Received for publication January 4, 1939)

The clinical differentiation of obstructive jaundice from that due to derangements of the liver is frequently impossible despite careful history taking and physical examination and the employment of many types of diagnostic procedures. Patients with grave hepatitis are often subjected to the added hazard of an anesthetic and laparotomy to rule out possible biliary tract obstruction, while conversely, exploration may be delayed perilously long in cases of obstruction in the hope that the jaundice will subside spontaneously.

In a previous preliminary report (1) the author has described a simple test by which disturbances in the hepatic parenchyma may be recognized by noting the capacity of the serum in these cases to flocculate a colloidal suspension of a cephalincholesterol complex. This test can be performed in any adequately equipped routine medical laboratory, since the reagents are few and relatively stable and no costly apparatus is required.

\section{TECHNIQUE FOR FLOCCULATION TEST}

A stock solution is prepared by dissolving $100 \mathrm{mgm}$. of sheep brain cephalin 1 and $300 \mathrm{mgm}$. of cholesterol in

1 The cephalin employed in the flocculation tests was prepared and kindly furnished by Dr. Erwin Chargaff of the Department of Biological Chemistry, College of Physicians and Surgeons, Columbia University. The process for preparation was as follows :

Sheep brains were dehydrated by 3 extractions with acetone and the dry tissue powder was 3 times extracted with ether (free of peroxides). The ether extracts were concentrated in vacuo and the crude cephalin was precipitated by the addition of 4 volumes of absolute alcohol. The resulting precipitate was dissolved in the minimum amount of ether, the accompanying cerebroside impurities were precipitated by chilling and removed by centrifugation. The supernatant ether solution was again precipitated with 4 volumes of absolute alcohol, chilled, and the precipitate filtered, washed with alcohol and acetone, and desiccated. The cephalin preparation is a brown powdery material containing traces of other lipids. These, however, do not feature in the reaction.
$8 \mathrm{cc}$. of ether (Squibb's anesthesia). This solution can be kept many months without deterioration in a well stoppered container. An emulsion of a cephalin-cholesterol complex may be prepared by adding (slowly and with stirring) $1 \mathrm{cc}$. of the stock ether solution to $35 \mathrm{cc}$. of freshly distilled water warmed to 65 to $70^{\circ} \mathrm{C}$. and then heating slowly to boiling. The mixture is allowed to simmer until the final volume is reduced to $30 \mathrm{cc}$. During the heating, all coarse granular clumps are dispersed to a stable, milky, translucent emulsion and all traces of ether are driven off. After cooling to room temperature the preparation is ready for testing, which consists of adding $1 \mathrm{cc}$. of the emulsion to a test tube (preferably a centrifuge tube) containing $0.2 \mathrm{cc}$. of the patient's serum diluted with $4 \mathrm{cc}$. of normal ( 0.85 per cent) saline. After thorough shaking and stoppering with cotton, the tube is allowed to stand undisturbed at room temperature and notation is made at the end of twenty-four and fortyeight hours as to the amount of flocculation and precipitation that has taken place. With normal human sera the emulsion remains as a stable homogeneous suspension but with sera from patients with diffuse hepatitis the lipoid material tends to flocculate and precipitate to the bottom of the tube. A ++++ reaction indicates a complete precipitation leaving the supernatant liquid water clear. Gradations of the reaction between negative and ++++ are designated in terms of,+++ , and +++ . No test should be regarded as negative until forty-eight hours have elapsed without flocculation.

Few precautions are necessary. The serum should preferably be fresh or preserved at ice box temperature. Plasma also may be used but the presence of various anticoagulants creates uncontrollable uncertainties. The lipid emulsion, if properly prepared, remains stable for many days but comparable results can be expected only if it is prepared freshly on the day it is to be used. It is important to measure accurately the various ingredients and to employ only carefully washed glassware. Traces of heavy metals or strong acids may give rise to erroneous positive flocculation.

\section{Diagnostic significance}

Over nine hundred sera from normal individuals or from patients with no demonstrable hepatic disorders have been examined in the manner described and, with the exception of one 


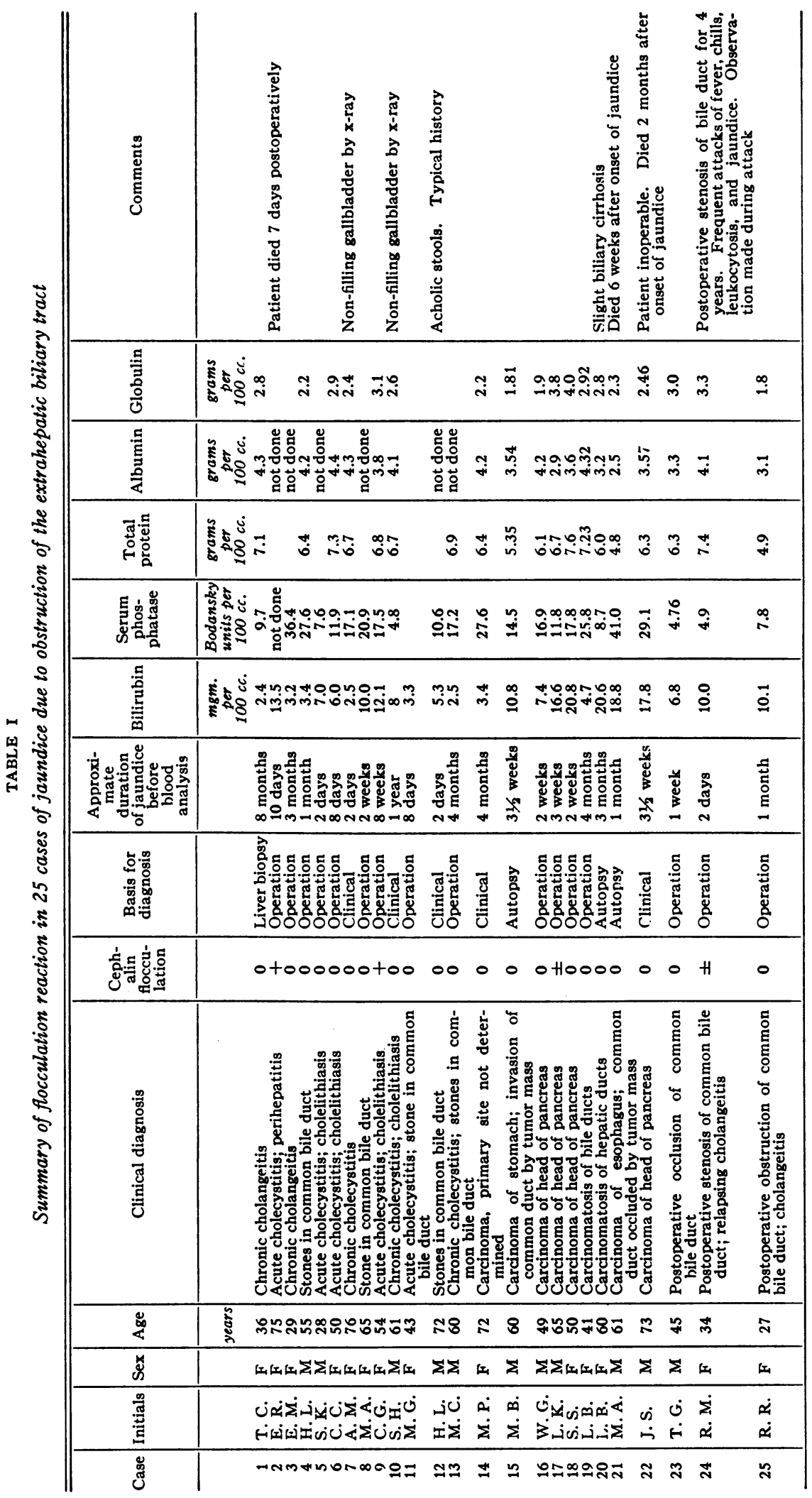


healthy medical student, no significant flocculation reactions have been observed.

In a like manner the sera from twenty-five cases of obstructive jaundice have been tested and these also, irrespective of the cause of the obstruction, have failed to produce significant flocculation (Table I). In several instances a \pm or + reaction has been noted in the forty-eight-hour reading. This finding presumably indicates mild hepatitis associated with the obstructive process. Even in cases of long standing biliary obstruction with secondary fibrosis in the liver, the test usually remains negative.

In contrast to the findings in obstructive jaundice, the serum from thirty-three of thirty-eight cases of jaundice due to hepatitis, catarrhal jaundice, and cirrhosis have produced a prompt, strong, flocculation reaction (Table II). The diagnosis has been established in these cases by histological examination of the liver tissue obtained at operation or autopsy, or by a clinical course so typical of "catarrhal jaundice" that there is little question as to the nature of the disorder.

A number of these cases have been tested repeatedly during the course of their disease and a close correlation always has been demonstrable between the clinical severity and the degree of flocculation. The following brief case report illustrates this point.

Case 4 (Table II). Hospital Number 410158. Male; age 28 years; occupation-clerk.

Diagnosis: Acute hepatitis-unknown etiology.

Patient was admitted to the Clinic, January 5, 1938, complaining of jaundice for 1 week. He had always been healthy, had had no indigestion, no exposure to industrial poisons, no previous medications, used alcohol infrequently. There was no history of preceding infection.

Present illness began ten days previously with malaise, anorexia, and nausea. Three days later patient noted light stools and dark urine. Increasing jaundice had been present for the past week. There was no pain over the liver. Slight itching of the skin was present.

Physical examination. Patient was intensely jaundiced, well nourished, and well developed. Sensorium was clear. Liver edge was $2 \mathrm{~cm}$. below the costal margin, and not tender. Spleen was not palpable. There was no ascites.

Clinical course. Patient was maintained on a high carbohydrate régime, and jaundice gradually subsided during the ensuing month. There was no fever; no anemia, and no leukocytosis. Wassermann was negative; sedimentation rate $6 \mathrm{~mm}$. in 1 hour. Stools were light but positive for urobilin by the mercuric chloride test. Urine showed decreasing amounts of bile during the month of jaundice. Patient's health has been excellent since illness.

Chemical studies of the blood in correlation with the flocculation test are shown in Table III. It will be noted in this case that the flocculation test agrees well with the clinical course while at the same time the total protein and the albuminglobulin ratio show no significant alterations.

The cephalin-cholesterol flocculation test is also of value in those instances where the clinical data are confusing or actually misleading.

Case 20 (Table II). Hospital Number 558088. Male; age 63 years; occupation-cabinet maker.

Complaint. Deepening jaundice for one month. General health was always excellent until six months previously when he first noticed a sensation of fullness across the epigastrium after meals. There was no actual pain. The attacks usually lasted about one hour and subsided spontaneously. One month before entering the clinic he noticed jaundice, light colored stools, and dark urine. His appetite became poor, bowels remained regular. $\mathrm{He}$ lost about ten pounds in weight. There was no previous exposure to drugs or chemicals.

Physical examination. The patient was an obese elderly Dutchman showing recent loss of weight. $\mathrm{He}$ was moderately jaundiced but did not complain of itching. A firm mass was palpable in the upper right quadrant which could be taken for either liver or an enlarged gallbladder. The spleen was not felt. There was no demonstrable ascites.

Laboratory findings. Hemoglobin 15.4 grams per cent; erythrocytes 5,050,000; leukocytes 7,000; Wassermann negative; stools acholic; urine contained bile. Serum bilirubin was $14.1 \mathrm{mgm}$. per cent, serum phosphatase 4.1 Bodansky units; serum protein 6.6 per cent; serum albumin 3.2 per cent; serum globulin 3.4 per cent; and blood amylase 19.8 units.

The presumptive diagnosis was obstructive jaundice. Support for this opinion was strengthened by the $x$-ray finding of distortion of the second portion of the duodenum compatible with an infiltrative lesion in the region of the pancreas. The cephalin flocculation test was ++++ , a finding to be expected with intrahepatic disease rather than with biliary obstruction.

The patient was explored surgically for diagnosis. The liver was found enlarged and firm. The gallbladder was not abnormal. There was an induration in the region of the head of the pancreas (probably inflammatory in nature) which was not obstructing the common bile duct.

A section of the liver taken at operation revealed hepatitis and cirrhosis of the portal type. The lobules were irregular in size and shape. The liver cells varied in appearance. A number were vacuolated and some contained bile pigment. An appreciable number of the cells contained two or more nuclei. The connective tissue septa were unusually thick and prominent. There was 


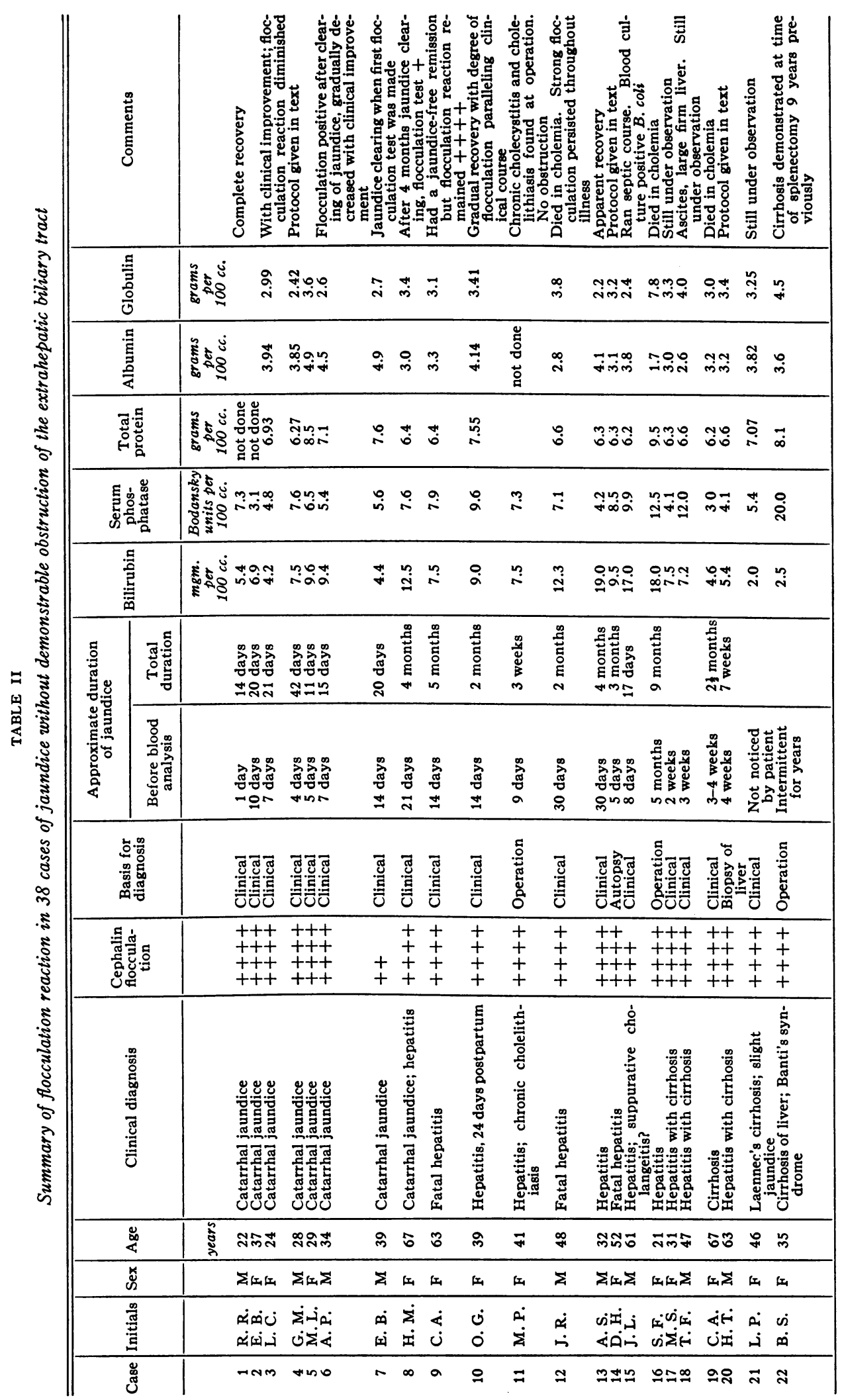




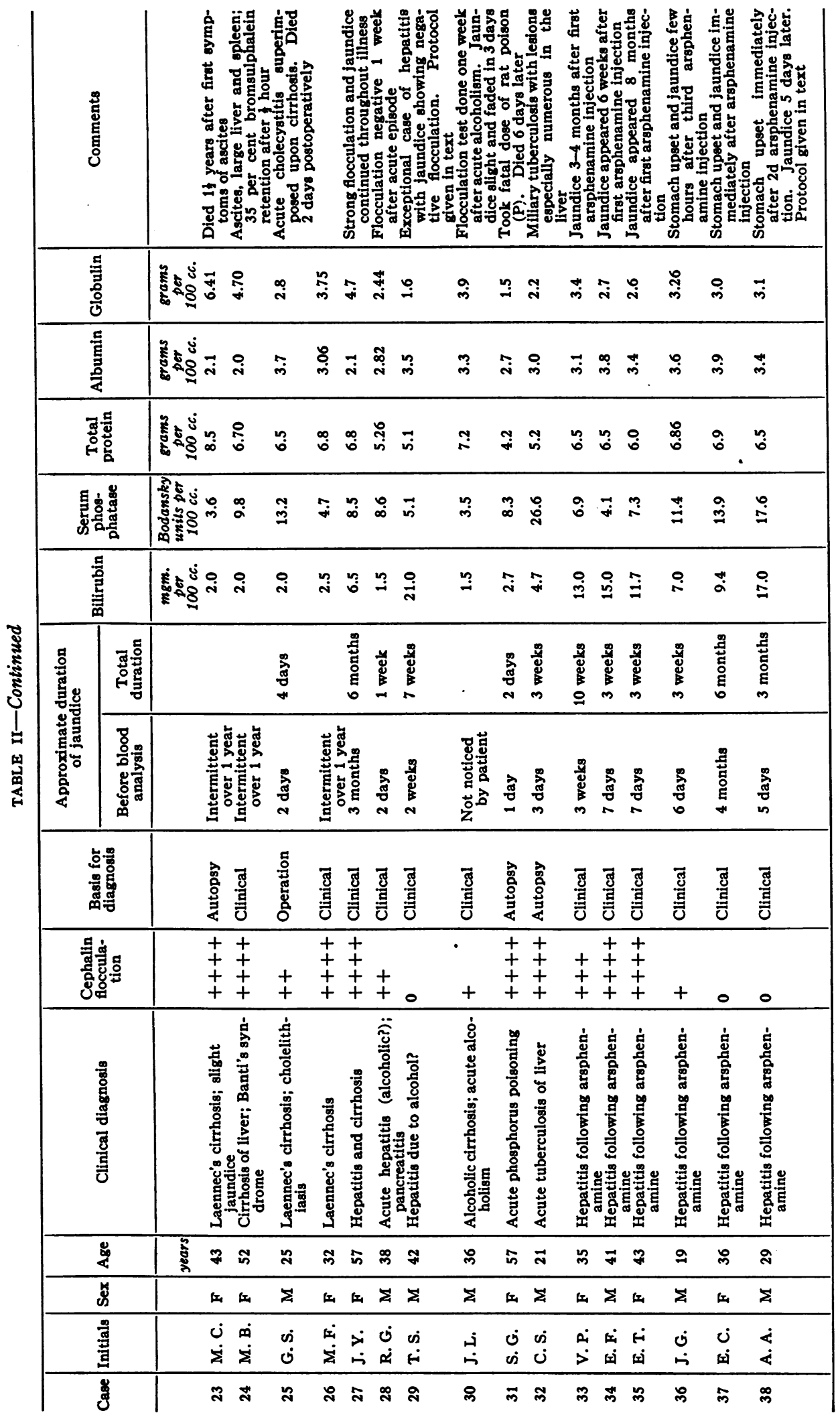


TABLE III

Blood chemistry studies, Patient 410158, showing correlation with cephalin-cholesterol flocculation test

\begin{tabular}{|c|c|c|c|c|c|c|c|}
\hline Date (1958) & January 6 & January 12 & January 20 & January 29 & February 7 & February 14 & April 26 \\
\hline $\begin{array}{l}\text { Serum bilirubin, mgm. per } 100 \mathrm{cc} \text {. } \\
\text { Serum nonprotein nitrogen, mgm. } \\
\text { per } 100 \text { cc. } \\
\text { Serum phosphatase, Bodansky units } \\
\text { per } 100 \mathrm{cc} \text {. (Normal } 1 \text { to } 4 \text { units) } \\
\text { Serum cholesterol, mgm. per } 100 \mathrm{cc} \text {. } \\
\text { Serum sugar, mgm. per } 100 \mathrm{cc} \text {. } \\
\text { Serum total protein, grams per } \\
\quad 100 \text { cc. } \\
\text { Serum albumin, grams per } 100 \mathrm{cc} \text {. } \\
\text { Serum globulin, grams per } 100 \mathrm{cc} \text {. } \\
\text { Degree of icterus } \\
\text { Flocculation test }\end{array}$ & $\begin{array}{c}7.0 \\
4.2 \\
2.8 \\
\text { Intense } \\
++++\end{array}$ & $\begin{array}{l}\text { Intense } \\
++++\end{array}$ & $\begin{array}{l}\text { Intense } \\
\text { Not done }\end{array}$ & $\begin{array}{c}27.5 \\
7.6 \\
309 \\
77 \\
6.3 \\
3.9 \\
2.4 \\
\text { Clearing } \\
++\end{array}$ & $\begin{array}{c}\text { Slight } \\
+\end{array}$ & $\begin{array}{l}21 \\
2.5 \\
2.9\end{array}$ & $\begin{array}{c}\text { Completely } \\
\text { absent } \\
0\end{array}$ \\
\hline
\end{tabular}

marked irregular proliferation of the bile duct epithelium. About the biliary ramifications in the fibrous connective tissue were inflammatory cell foci composed predominantly of plasma cells, lymphocytes, and rare polymorphonuclear leukocytes. No bile was seen in the ducts. The patient's jaundice cleared spontaneously. He has been symptom-free for the past three months.

\section{Prognostic significance}

The flocculation test is of considerable value prognostically in cases of hepatitis. Many patients with mild attacks develop negative reactions before the icterus has completely subsided. For this reason, performing the test late in the course of the disease may yield little of differential diagnostic value. However, finding a negative flocculation at this stage is a favorable indication, since no relapses or evidence of persisting liver disease have yet been observed in a case of acute hepatitis once the reaction has returned to normal. On the other hand, the maintenance of a strongly positive flocculation reaction, irrespective of changes in the degree of jaundice, is of grave import and is usually indicative of active progressive liver degeneration.

The following abstract indicates the typical findings in a case of intractable hepatogenous jaundice.

Case 14 (Table II). Hospital Number 557929. Female; age 52 years; housewife.

Patient lived in Colombia, South America, until the age of twenty and has had no serious illnesses except chronic malaria in early adult life. General health was excellent. She has used considerable alcohol (7 oz. gin) daily for years. Her diet in the past year has been inadequate and especially low in vitamin content. She has lost 20 pounds in this interval and has noticed progressive weakness. Three months before admission to the clinic, paresthesias, and hyperesthesias developed in the lower extremities. One month later she complained of anorexia, constipation, belching, distention, and attacks of sharp intermittent epigastric pain. Five days before admission she noticed jaundice and dark urine for the first time. The stools remained brown. There was no itching of the skin.

Physical examination. The patient was an emaciated, tired looking, middle-aged woman. She was moderately jaundiced and showed on the face and body a number of spider angiomata. The liver, which was enlarged $8 \mathrm{~cm}$. below the costal margin, seemed firm and irregular. The spleen was not palpable. The knee jerks and ankle jerks were absent, and there was considerable hyperesthesia of the lower limbs.

Course. A painful friction rub soon appeared in the region of the liver and ascites requiring frequent tappings developed. She became progressively weaker and more jaundiced in spite of high carbohydrate administration and large intake of vitamins both in the food and parenterally. She died in stupor three months after the onset of jaundice.

Laboratory findings. Hemogloblin 8 grams per cent; erythrocytes $2,590,000$; leukocytes 16,400 ; polymorphonuclears 86 per cent; erythrocyte sedimentation rate $82 \mathrm{~mm}$. in 1 hour. Urine was negative except for choluria. Stools were brown and contained urobilin; no occult blood was present. X-ray examinations of the chest and gastro-intestinal tract revealed no evidence of malignancy. Wassermann was negative; gastric analysis, free $\mathrm{HCl}$ absent; serum bilirubin, $9.5 \mathrm{mgm}$. per cent direct; serum phosphatase 8.5 Bodansky units; blood cholesterol 208 mgm. per cent; serum protein 6.2; serum albumin 3.1 per cent; serum globulin 3.2 per cent; and euglobulin 0.6 per cent. The bromsulphalein test showed 60 per cent dye retention after 30 minutes. Takata-Ara test +++ .

The cephalin flocculation test was performed one week after the onset of jaundice and again a short time before death. In both instances the reaction was strongly posi- 
tive. In the meantime total serum protein dropped to 5.2 per cent, serum albumin to 2.3 per cent, and serum globulin to 2.9 per cent.

Histologically, the liver lobulation was completely distorted. There was central and periportal fibrosis with marked polymorphonuclear leukocytic infiltration in the periportal connective tissue. The most prominent feature was the jaundice and necrosis of the more central liver cells. Many had hyaline droplets and occasionally others showed leukocytes within the boundaries of the disintegrating cells. There was proliferation of bile ducts in the portal areas, many of which were also infiltrated by polymorphonuclear leukocytes.

\section{The flocculation test in hepatitis due to known toxic agents}

Patients with jaundice following administration of arsphenamine may be indistinguishable by flocculation reactions from the idiopathic types of hepatitis already described. On the other hand, of the four instances, in our records, of hepatitis with icterus failing to give a positive reaction, three are attributable to the recent use of this drug.

The following abstract deals with this type of case.

Case 38 (Table II). Hospital Number 551044. Male; age 29 years; occupation-cashier.

Patient's general health was excellent. Initial injection of arsphenamine had been two months previously for an asymptomatic positive Wassermann reaction. There had been no discomfort after the first injection but about four hours after the second treatment, one month later, he developed a chill, vomited, and became prostrated. He continued to run fever and developed puffy eyes, anorexia, and pain across the upper abdomen. Jaundice was noticed five days after the arsphenamine administration accompanied by itching, dark urine, and light stools.

Physical examination. Patient was deeply jaundiced. There was distressing pruritis of the skin. Liver and spleen were not palpable.

Course. Patient's jaundice subsided slowly over a period of three months. During this period he ran an irregular fever of about $100^{\circ}$. He has subsequently made a satisfactory recovery.

Laboratory findings. Hemoglobin 12 grams per cent; erythrocytes $4,250,000$; leukocytes 8,400 ; polymorphonuclears 58 per cent; eosinophiles 8 per cent. Stools were acholic at onset, but contained bile later. Erythrocyte sedimentation rate was $113 \mathrm{~mm}$. in one hour. The urine showed a heavy trace of bilirubin. X-ray examinations subsequently have revealed a normal gallbladder. Serum phosphatase was 17.6 Bodansky units; serum bilirubin $17.0 \mathrm{mgm}$. per cent; serum cholesterol 580 ; serum protein 6.5 per cent; serum albumin 3.4 per cent; serum globulin 3.1 per cent. Chemical studies made weekly during the course of his illness showed a gradual return to more normal figures.

The flocculation test on this patient was repeatedly negative.

In contrast to the group of post-arsphenamine cases showing strong flocculation reactions and resembling idiopathic hepatitis, the negatively reacting group is characterized by prompt onset of disability and jaundice following arsphenamine injection, intense itching of the skin, little disturbance of the albumin: globulin ratio, and elevated serum phosphatase. Flood, Gutman, and Gutman (2) have already noted the elevation of serum phosphatase in about half of their cases of post-arsenical hepatitis and have pointed out that the high values encountered would accord better with an obstructive process. The absence of flocculation also supports an assumption that the mechanism of jaundice production in certain of the post-arsphenamine cases is different from that operating in idiopathic hepatitis. It is of practical importance that a negative flocculation test may lead to the erroneous diagnosis of obstructive jaundice in patients who have recently received arsphenamine.

Instances of liver damage due to other recognized toxic agents have been too few to warrant any comparison with the post-arsenical group. One case of fatal phosphorus poisoning (Case 557927) showed a ++++ reaction. On the other hand, a single unexplained case of hepatitis with jaundice, which followed soon after acute alcoholism, and gave a negative flocculation test, has been encountered.

Case 29 (Table II). Hospital Number 557966. Male; age 42 years; occupation-fireman.

Two days following heavy overindulgence in beer and whiskey, the patient noticed dark urine and light stools followed by jaundice. He vomited once. There was moderate itching of the skin, but no abnormal bleeding. General health always had been excellent. Patient has used alcohol regularly for years, with occasional episodes of excessive drinking. He had had no previous medications nor exposure to injurious chemicals. Diet had been adequate. He entered the clinic after increasing jaundice for two weeks.

Physical examination. Patient was well nourished, afebrile, and intensely jaundiced. The liver extended to the level of the umbilicus, and was not tender. Tip of the spleen was palpable. There was questionable ascites and slight pitting edema of the ankles. 
Course. Jaundice gradually cleared in seven weeks and liver decreased considerably in size. Patient has been well and active since recovery.

Laboratory findings. Hemoglobin 14 grams per cent; erythrocytes 4,400,000; leukocytes 6,600 ; polymorphonuclears 74 per cent; erythrocyte sedimentation rate 3 $\mathrm{mm}$. in one hour. Urine was negative except for bile ++++ . Stools contained urobilin. X-ray of the gastro-intestinal tract revealed no abnormalities. Kline test was negative. Serum bilirubin was $21.0 \mathrm{mgm}$. per cent; serum phosphatase 5.1 Bodansky units; serum cholesterol $121 \mathrm{mgm}$. per cent; serum protein 5.1 per cent; serum albumin 3.5 per cent; serum globulin 1.6 per cent. Cephalin flocculation was repeatedly negative.

A negative reaction would have been more significant had it been obtained earlier in the course of his disease, since a number of non-jaundiced, acute alcoholics with temporary enlargement of the liver have shown a positive flocculation reaction during a brief period only. It is suggestive, however, that the patient was suffering from a toxic hepatitis due to alcohol and that the mechanism of jaundice production may differ with the various types of liver injury.

\section{The flocculation test in jaundice due to miscel- laneous causes}

Cases of jaundice due to cholangeitis, liver abscess, and new growth have been too few in our series to establish an evaluation of the flocculation test in these conditions. Single or circumscribed suppurative lesions in the liver are associated generally with a negative reaction while cases in which the process is multiple or widely disseminated give a positive reaction. Carcinomatosis of the liver, both primary and metastatic, usually is accompanied by a negative reaction. Several cases, however, with metastases in the liver from primary tumors of the colon, esophagus, etc., have shown a positive reaction.

All four cases of hemolytic jaundice studied have failed to show flocculation. On the other hand, jaundice appearing during acute or chronic infections such as pneumonia or septicemia is usually accompanied by a positive test. This finding tends to indicate that icterus occurring during infection is secondary to changes in the liver rather than to excessive blood destruction as is sometimes assumed.

\section{Comparison of the flocculation reaction with liver function tests}

With the exception of a few post-arsphenamine cases, the cephalin-cholesterol flocculation test has proved to be a more sensitive and more accurate index of active disturbances of liver parenchyma than any of the so-called liver function tests. Occasionally, hepatic insufficiency may be demonstrable by poor bromsulphalein excretion or other methods when the flocculation test is consistently negative. This has been observed chiefly among patients with extensive neoplastic involvement or with chronic cirrhosis in whom the process is stationary so far as can be determined by long periods of observation. It is probable that the replacement of active liver cells by new growth or scar tissue in these instances, rather than inflammatory or degenerative processes, accounts for the impairment of hepatic function. Like the finding of albuminuria, which is often a better early indication of active kidney disease than renal function tests, so, a positive flocculation may disclose certain types of liver derangements when the usual liver function tests are equivocal. Comparisons with other procedures have not been made in all cases, but no strict correlation of the degree of flocculation has been established with the bromsulphalein excretion, hippuric acid formation, or levulose tolerance test. Neither does it necessarily parallel the Takata-Ara reaction, the formol gel test, the serum bilirubin or serum cholesterol content, or quantitative changes in any of the recognized protein constituents. It may be positive or negative irrespective of the Wassermann reaction or erythrocyte sedimentation rate.

\section{Mechanism of the flocculation reaction}

The mechanism of the flocculation test is still under investigation and will be reported elsewhere. The 'factors upon which the phenomenon depends are probably comparable to those involved in the flocculation tests for syphilis as described by Eagle (3). In brief, there is evidence supporting the assumption that a strongly flocculating serum contains a nitrogen bearing constituent in the globulin fraction, which, during the reaction, becomes attached to the surface of the cephalin-cholesterol particles. The film of adsorbed protein probably brings about changes in surface potential and increase of cohesive forces between the colloidal elements. The flocculation reaction depends upon the specific properties of certain cephalins. It is not obtained with cholesterol or cephalin alone or with emulsions composed of cholesterol and other 
lipids such as egg lecithin. The rôle of cholesterol in the reaction is probably that of orientating and furnishing a vehicle for the cephalin component. The nature of the flocculating substance and the reason for its presence during the course of certain hepatic disturbances is still speculative.

\section{CONCLUSIONS}

1. Emulsions prepared from mixtures of sheep brain cephalin and cholesterol are not flocculated usually by normal human serum or by serum from patients with obstructive jaundice.

2. Cephalin-cholesterol emulsions are flocculated by sera from patients with active disturbances of liver parenchyma.

3. Jaundice due to biliary obstruction may be distinguished usually from hepatogenous jaundice by the cephalin-cholesterol flocculation test.

4. The degree of flocculation parallels the severity of active liver disease and may therefore be employed prognostically in estimating the degree and persistence of the active process.
5. Certain patients with jaundice appearing immediately following salvarsan injections may give a negative flocculation reaction and thus simulate obstructive jaundice.

6. The flocculation test may be regarded as an index of disturbance of liver parenchyma and does not parallel hepatic function tests.

7. The mechanism of the flocculation test probably depends upon the capacity of an altered globulin constituent of the serum to become affixed to the colloidal elements of the emulsion.

\section{BIBLIOGRAPHY}

1. Hanger, Franklin M., The flocculation of cephalincholesterol emulsions by pathological sera. Tr. A. Am. Physicians, 1938, 53, 148.

2. Flood, Charles A., Gutman, Ethel Benedict, and Gutman, Alexander B., Phosphatase activity, inorganic phosphorous and calcium of serum in disease of liver and biliary tract. Arch. Int. Med., 1937, 59, 981.

3. Eagle, Harry, Laboratory Diagnosis of Syphilis. Mosby, St. Louis, 1937. 